\title{
General report: session on connections
}

\author{
J.P. Jaspart \\ Department MSM, University of Liège, Quai Banning 6, B-4000 Liège, Belgium
}

\begin{abstract}
As a result of a world-wide intensive research activity, a new design concept for structural moment resistant joints has been suggested and implemented in design codes. In the present paper, its background is first briefly described and the main contributions to its development are presented. As a matter of fact, because of the high number of past and ongoing researches, reports and papers devoted to this topic, an exhaustive list of all these works could not be established in a limited number of pages.
\end{abstract}

The possibilities of extension of the new design concepts, which have been first developed for steel beam-tocolumn joints under static loading, are particularly pointed out. This aspect appears quite important as in the near future it should provide designers with a unified design approach for structural joints whatever their loading, their configurations and the nature of their constitutive material(s).

Keywords : Structural joints ; building frames ; economy ; characterisation ; modelling ; classification ; idealisation ; experimentation ; fitting ; mechanical model ; analytical model ; numerical model ; practical design tool ; static loading; earthquake ; fire

\section{Introduction}

In the last fifteen years, much research work has been devoted world-wide to structural moment resistant joints and their influence on the resistance and the stability of building frames. All these researches have progressively led to a deep understanding of the joint behaviour, to the development of design tools for the avaluation of the mechanical properties of the joints and to guidelines and recommendations for the design of building frames including the joint behaviour. The motivation of these works is of a scientific nature, but it is also clearly linked to the economical benefit which results from a better considération of the importance of the joint design as far as fabrication and erection costs are concerned.

The new concept for joint design has been first developed for beam-to-column steel joint configurations between $\mathrm{H}$ or I profiles and subject to static bending and shear forces. More recent works have allowed to extend the concept to composite joints but also to other types of configurations such as beam-to-beam ones, beam splices and column bases. Further actions are now in progress to apply this new design approach to other types of profiles (tubular sections, built-up sections, ...), to other loading conditions (fire, earthquakes, ...) and to other materials (timber, precast concrete, ...).

In this article, the new design concept is described and the significant scientific contributions to its development are commented on

\section{A consistent approach for structural joints}

The rotational behaviour of actual joints is well recognised as being often intermediate between the two extreme situations, i.e. rigid or pinned.

Consider now the bending moments and the related rotations at a joint (Fig. 1):

When all the different parts in the joint are sufficiently stiff (i.e. ideally infinitely stiff), the joint is rigid, and there is no difference between the respective rotations at the end of the members connected at this joint (Fig. 1a). The joint experiences a single global rigid-body rotation which is the nodal rotation in the commonly used 
analysis methods for framed structures.

Should the joint be without any stiffness, then the beam will behave just as simply supported whatever the behaviour of the other connected member(s) (Fig. 1b). This is a pinned joint.

For intermediate cases (non zero and non infinite stiffness), the transmitted moment will resuit in a différence $\phi$ between the absolute rotations of the two connected members (Fig. 1c). The joint is semi-rigid in these cases.

Fig. 1. Classification of joints according to rotational stiffness.

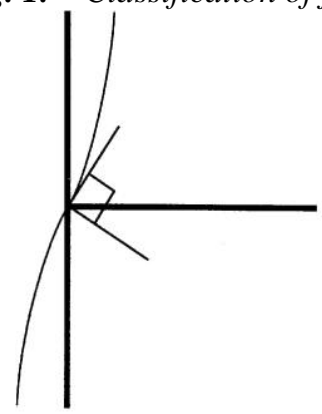

(a) Rigid joint

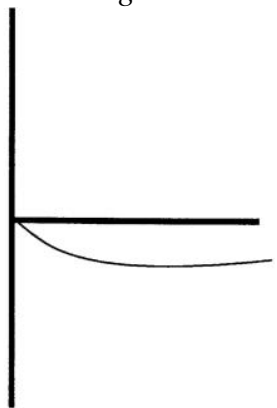

(b) Pinned joint

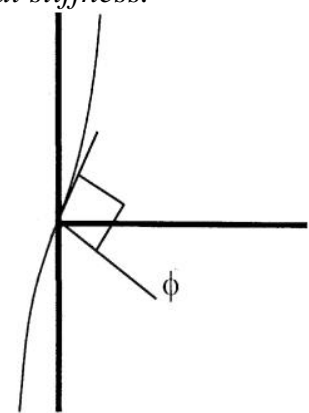

(c) Semi-rigid joint

The simplest means for representing the concept is a rotational (spiral) spring between the ends of the two connected! members. The rotational stiffness $S$ of this spring is the parameter that links the transmitted moment $M_{j}$ to the relative rotation $\phi$. It is defined as the slope of the so-called moment-rotation curve $M_{j^{-}} \phi$ which depends on the joint properties.

At the global analysis stage, the effect of having semi-rigid joints instead of rigid or pinned joints is to modify not only the displacements, but also the distribution and magnitude of the internai forces throughout the structure.

As an example, the bending moment diagrams in a fixed-base simple portai frame subjected to a uniformly distributed load are given in Fig. 2 for two situations, where the beam-to-column joints are respectively either pinned or semi-rigid. The same kind of consideration holds for deflections.

The concept of semi-rigid joints is introduced in some different codes, and in particular in Eurocode 3 Part 1.1 [1] for the design of steel structures under static loading.

Fig. 2. Elastic distribution of bending moments in a simple portai frame.
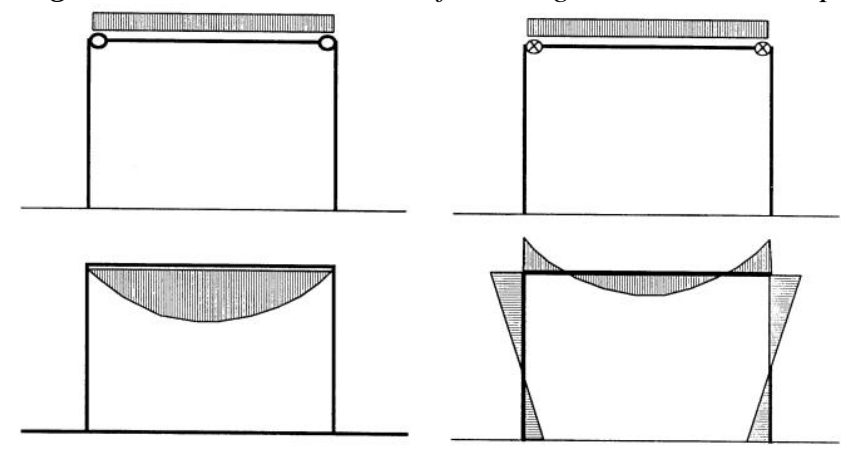

(a) Pinned joints

(b) Semi-rigid joints 


\section{The merits of the consistent approach for structural joints}

Both the Eurocode 3 requirements and the desire to model the behaviour of the structure in a more realistic way leads to the consideration of the semi-rigid behaviour when necessary.

Many designers would stop at that basic interpretation of the code and hence would be reluctant to confront the implied additional computational effort involved. Obviously a crude way to deal with this new burden will be for them to design joints that will actually continue to be classified as being either pinned or fully rigid.

However such properties will have to be proven at the end of the design process and, in addition, such joints will certainly be found to be uneconomical in a number of situations.

It should be noted that the concept of rigid and pinned joints still exists in Euro-code 3. It is accepted that a joint which is almost rigid, or almost pinned, may still be considered as being truly rigid or truly pinned in the design process. How to judge whether a joint can be considered as rigid, semi-rigid or pinned depends on the comparison between the joint stiffness and the frame stiffness.

The designer is strongly encouraged to go beyond this "all or nothing" attitude. Actually it is important to consider the benefits to be gained from the semi-rigid behaviour of joints. Those benefits can be brought in two ways:

1. The designer decides to continue with the practice of assuming — sometimes erroneously — that joints are either pinned or fully rigid. However, proper consideration has to be given to the influence that the actual behaviour of the joints has on the global behaviour of the structure, i.e. on the precision with which the distribution of forces and moments and the displacements have been determined. This may not prove to be easy when the joints are designed at a late stage in the design process since some iterations between global analysis and design checking may be required. Nevertheless, the following situations can be foreseen:

- So that a joint can be assumed to be rigid, it is common practice to introduce web stiffeners in the column.

Eurocode 3 now provides the means to check whether such stiffeners are really necessary for the joint to be both rigid and have sufficient resistance. There are practical cases where they are not needed, thus permitting the adoption of a more economical joint design.

- When joints assumed to be pinned are later found to have fairly significant stiffness (i.e. to be semi-rigid), the designer may be in a position to reduce beam sizes. This is simply because the moments carried by the joints reduce the span moments in the beams.

2. The designer decides to give consideration, at the preliminary design stage, not only to the properties of the members but also to those of the joints. It may be shown [2] that this new approach is not at all incompatible with the sometimes customary separation of the design tasks between those who have the responsibility for conceiving the structure and carrying out the global analysis and those who have the responsibility for designing the joints. Indeed, both tasks are very often performed by different people, or indeed, by different companies, depending on national or local industrial habits. Adopting this novel early consideration of joints in the design process requires a good understanding of the balance between, on the one hand, the costs and the complexity of joints and, on the other hand, the optimisation of the structural behaviour and performance through the more accurate consideration of joint behaviour for the design as a whole. Two examples are given to illustrate this:

- It was mentioned previously that it is possible in some situations to eliminate column web stiffeners and therefore to reduce costs. Despite the reduction in its stiffness and, possibly, in its strength, the joint can still be considered to be rigid and be found to have sufficient strength. This is shown to be possible for industrial portal frames with rafter-to-column haunch joints in particular, but other cases can be envisaged.

- In a more general way, it is worthwhile to consider the effect of adjusting the joint stiffness so as to strike the best balance between the cost of the joints and the cost of the beams and the columns. For instance, for braced frames, the use of semi-rigid joints, which are not necessarily more costly than the pinned joints, leads to reducing the beam sizes. For unbraced frames, the use of less costly semi-rigid joints, instead of the rigid joints, may lead to increased beam sizes and possibly column sizes.

Of course the task may seem a difficult one, and this is why a design handbook devoted to this new concept has recently been published [3]. The whole philosophy could be termed as "Because you must do it, take advantage of $i t^{\prime \prime}$. The designer has therefore the choice between a traditionalist attitude, where something may often be gained, and an innovative attitude, where the most economical result [4] may best be sought.

It is important to stress the high level of similarity that exists between the member and joint responses. This topic is addressed in the next section. 


\section{A parallel between member sections and joints}

Member cross-section behaviour may be considered through an $M-\phi$ curve for a simply supported beam loaded at mid-span ( $M$ : bending moment at mid-span; $\phi$ : sum of rotations at the span ends). Joint behaviour will be considered through a similar relationship, but with $M=M_{j}$ being the bending moment transmitted by the joint and $\phi$ being the relative rotation between the connected members. Those relationships have similar shapes as illustrated in Fig. 3. To fiexural stiffness $E I / L$ and the design resistance $M_{b . R d}$ of the member correspond the initial stiffness $S_{j, \text { ini }}$ and the design resistance $M_{j . R d}$ of the joint.

According to Eurocode 3 member cross-sections are divided into four classes according to their varying ability to resist local instability, when partially or totally subject to compression, and the consequences this may have on the possibility for plastic redistribution. Therefore their resistance ranges from the full plastic resistance (class 1 and 2) to the elastic resistance (class 3 ) or a reduced elastic resistance (class 4).

The allocation of a cross-section to a specific class is governed by the assumptions on:

- The behaviour to be idealised for global analysis (i.e. class 1 will allow the formation of a plastic hinge and permit the redistribution of internal forces in the frame as loads are increased up to or beyond the design loads);

- The behaviour to be taken into account for local design checks (i.e. class 4 will imply that the resistance of the cross-section is based on the properties of a relevant effective cross-section rather than of the gross crosssection).

Fig. 3. M- $\phi$ characteristics for member cross-section and joint.
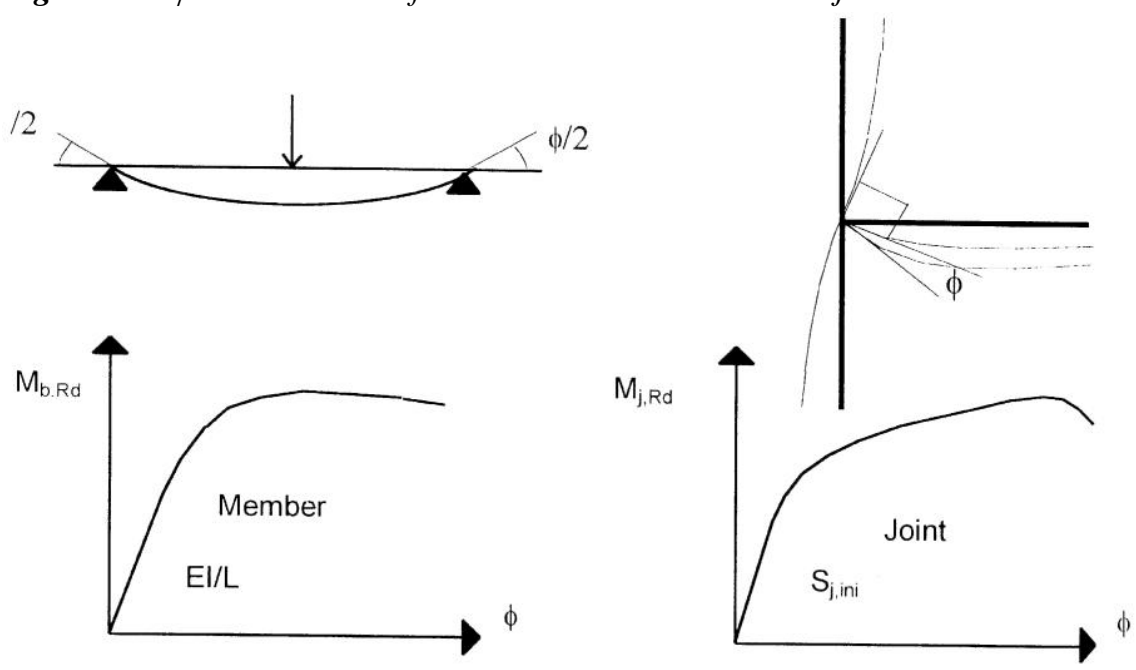

In Eurocode 3, the classification of a cross-section is based on the width-to-thickness ratio of the component walls of the section. Ductility is directly related to the amount of rotation during which the design bending resistance will be sustained. For joints, the rotation capacity concept is equivalent to the ductility concept for sections.

In a manner similar to that for member cross-sections, joints are classified in terms of ductility or rotation capacity. This classification is a measure of their ability to resist premature local instability and, even more likely, premature brittle failure (especially due to bolt failure) with due consequences on the type of global analysis allowed. The practical interest of such a classification for joints is to check whether an elasto-plastic global analysis may be conducted up to the formation of a plastic collapse mechanism in the structure, which implies such hinges in at least some of the joints.

Joints may therefore be classified according to both their stiffness and their ductility. Moreover, joints may be classified according to their strength. 
In terms of their strength, joints are classified as full-strength or partial-strength according to their resistance compared to the resistance of the connected members. For elastic design, the use of partial-strength joints is well understood. When plastic design is used, the main use of this classification is to foresee the possible need to allow a plastic hinge to form in the joint during the global analysis. In order to permit a further increase of loads beyond that corresponding to the formation of the hinge, a partial-strength joint may be required to act as a hinge from the moment when its plastic bending resistance is reached. In that case, the joint must also have sufficient ductility.

A parallel between member sections and partial-strength joints may also be identified in the case of cyclic loading under seismic action.

\section{The concept of joint representation}

For many years the research activity in the field of joints mainly concentrated on two aspects:

- the evaluation of the mechanical properties of the joints in terms of rotational stiffness, moment resistance and rotation capacity;

- the analysis and design procedures for frames including joint behaviour.

However, progressively, it has been understood that there were intermediate steps to consider in order to integrate in a consistent way the actual joint response into the frame analysis; this is known as the joint representation.

The joint representation includes four successive steps respectively named:

- the joint characterisation: i.e. the evaluation through appropriate means of the stiffness, resistance and ductility properties of the joints (full M- $\phi$ curves or key values);

- the joint modelling: i.e. the way on how the joint is physically represented in view of the frame analysis;

- the joint classification: i.e. the tool providing boundary conditions for the use of conventional types of joint modelling (e.g. rigid or pinned)

- the joint idealisation: i.e. the derivation of a simplified moment-rotation curve so as to fit with specific analysis approaches (e.g. linear idealisation for an elastic analysis).

The state of development and knowledge in these four domains is discussed in the following sections.

\section{Joint characterisation}

\subsection{Generals}

This paragraph gives an overview of the existing characterisation procedures by particularly highlighting their advantages and drawbacks.

The more accurate, but also expensive, way to characterise the deformability and the resistance of joints is the experimentation in laboratory. The use of this technique — which requires much money and time - is basically limited to research activities and can consequently not be recommended for daily practice.

The existence of numerous test results for a large variety of joint configurations and connection types led progressively some researchers to develop computerized databanks $[5,6]$. The low probability for the designer to find information for the specific joint he is studying and the risk to misinterpretate the results listed in the databank - no standardised procedure for the testing of joint exists at present - limit considerably the practical interest of these tools. On the other hand, it now appears clearly that the databanks have to be considered as quite valuable tools for the validation of mathematical models aimed at predicting the joint response on the basis of the geometrical and mechanical joint properties.

Most of the well-known mathematical models available in the literature are described by Nethercot and Zandonini [7]. They can be classified in four main categories:

- curve fitting;

- simplified analytical models;

- mechanical models;

- finite element analysis.

These categories are briefly presented hereafter. 


\subsection{Curve fitting}

Definition:

- Attempt to fit a mathematical representation to characteristic M- $\phi$ curves obtained by means of: experimental tests in laboratory; numerical simulations.

- Attempt to link the coefficients of the mathematical representation with physical parameters of the joint.

General advantages and/or disadvantages:

- Capacity of representing with extreme accuracy any shape of M- $\phi$ curve;

- Purely empirical $\rightarrow$ range of application limited to joints, the geometrical and mechanical properties which are similar to those considered when calibrating the formula.

- Inability to recognize that, depending on the relative actual values of the geometrical and mechanical parameters, the type of connection behaviour as well as the contribution of each component to the overall joint response may change significantly.

\subsection{Simplified analytical models}

Definition:

- Simplified analytical methods to predict the main characteristic values of the $M-\phi$ curves (initial stiffness, design moment resistance,...); this step requires the knowledge of the mechanical and geometrical properties of the joints.

- Verification of these analytical methods by comparison with test data or results of numerical simulations.

- Description of the $M-\phi$ behaviour by curve fitting using the calculated initial stiffness, plastic and/or ultimate moment,... in suitable mathematical expressions.

General advantages and/or disadvantages:

- Allow approximation of the form of the $M-\phi$ curves without resorting to testing;

- Still require empirical curve fitting to generate the full curve (but limited!);

- Special remark: Eurocode 3 Revised Annex $J$ [8] method refers basically to this section; it provides an original way to generate the $M-\phi$ curves.

\subsection{Mechanical models}

\section{Definition:}

- Set of rigid and deformable elements each representing the behaviour of specific parts of the joint.

- Non-linearity of the joint response is then accounted for by inelastic constitutive laws adopted for the deformable elements.

- These constitutive laws are obtained from test data, numerical simulations or analytical models.

General advantages and/or disadvantages:

- Really suitable for modelling provided that a knowledge of the load deformation curve of the key components is available.

- May be easily extended to different types of joint configurations and of connections provided the knowledge of the key components is available.

- Often require the use of computer programs to generate the $M-\phi$ curves.

\subsection{Finite element analysis}

Definition:

- Prediction of $M-\phi$ curves by means of a finite element analysis 
General advantages and/or disadvantages:

- Suitable to predict the response of welded joints.

- Sufficient ability to model the non-linear 3-D response of joints with bolted connections and in particular: the actual bolt action;

the contact phenomena;

the slips;

not always fully attained.

An updated list, with references, of existing models for each category may be found in [9].

From this description, it may be concluded that:

- The finite element analysis is not yet likely to be used to predict the semi-rigid response for any type of connection detailing and its use is reserved to research activities, even if significant progress has been achieved in the last years [10].

- The simplified analytical models and the mechanical models are characterised by a wider field of application than curve fitting; this results from the theoretical background of these two kinds of models. However, they have to be extended to other types of connections in order to cover the main needs of the designers.

- The simplified analytical models are the only ones — with the formulae resulting from curve fitting suitable for hand calculations.

\subsection{The component method}

Plenty of analytical models are available in the literature for different types of joint configurations and connection types. But progressively one of these models, because of the advantages it offers in comparison to the others, slowly became the reference and is now considered as such by most of the researchers. In particular it has been followed in Eurocode 3 Revised Annex $J$ [8]. It is known as the component method.

Roughly speaking the component method may be presented as the application of the well-known finite element method to the calculation of structural joints.

In the characterisation procedures, a joint is generally considered as a whole and is studied accordingly; the originality of the component method is to consider any joint as a set of "individual basic components". In the particular case of Fig. 4 (joint with an extended end-plate connection subject to bending), the relevant components are the following:

- compression zone:

column web in compression;

beam flange and web in compression;

- tension zone:

column web in tension;

column flange in bending;

bolts in tension;

end-plate in bending;

beam web in tension;

- in shear zone:

column web panel in shear.

Each of these basic components possesses its own level of strength and stiffness in tension, compression or shear. The coexistence of several components within the same joint element - for instance, the column web which is simultaneously subjected to compression (or tension) and shear - can obviously lead to stress interactions that are likely to decrease the strength and the stiffness of each individual basic component [11]; this interaction affects the shape of the deformability curve of the related components but does not call the principles of the component method into question again. 
Fig. 4. Joint with end-plate in bending.

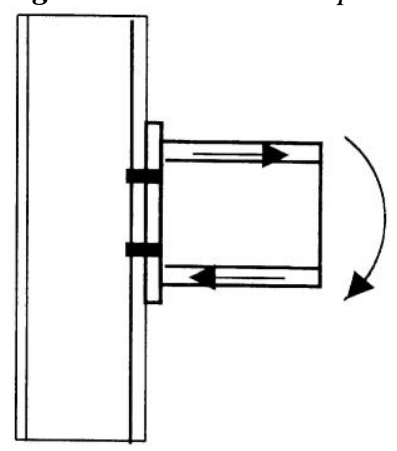

The application of the component method requires the following steps:

1. identification of the active components for the studied joint;

2. evaluation of the mechanical characteristics of each individual basic component (specific characteristics initial stiffness, design strength,... — or the whole deformability curve);

3. "assembly" of the components in view of the evaluation of the mechanical characteristics of the whole joint (specific characteristics — initial stiffness, design resistance, .... — or the whole deformability $M$ - $\varphi$ curve).

These three steps are schematically illustrated in Fig. 5 in the particular and simple case of a beam-to-column steel joint with a welded connection.

Fig. 5. Application of the component method to a welded steel joint (simplified bi-linear component and joint deformability curves).

Three steps
Iirst step:
Identification of the
components


As specified above, the parallelism with the finite element method is obvious. To "component" and "joint" may then be substituted the words "finite element" and "structure".

The assembly is based on a distribution of the internal forces within the joint. As a matter of fact, the external loads applied to the joint distribute, at each loading step, between the individual components according to the instantaneous stiffness and resistance of each component. Distributions of internal forces may be obtained through different ways as discussed in [9].

The application of the component method requires a sufficient knowledge of the behaviour of the basic components. To review all the publications devoted to this subject would be quite long and therefore references are made here to recent summary reports, in particular those prepared within the COST C1 European Action on "Control of the Semi-Rigid Behaviour of Civil Engineering Connections" (1992-1996).

The components active in the traditional steel joints have been deeply studied and recommendations for their characterisation are given in the Revised Annex $J$ of Euro-code 3 [8]. The combination of these components allows a wide range of joint configurations to be covered, which should largely be sufficient to satisfy the needs of practitioners as far as beam-to-column joints and beam splices in bending are concerned. The application is however limited to joints between $\mathrm{H}$ or I hot-rolled profiles or built-up ones with similar dimensions.

Some new fields of application have recently been investigated:

- Weak axis joints where the beam is connected to the web of an $\mathrm{H}$ or I column profile are characterised by an out-of-plane deformability of the column web under the tension and compression forces carried over by the beam. For this "column web in transverse compression and tension" component, stiffness and strength characterisation tools are now available [12]. Knowledge about this component allows the extension of the component method to joints where tubular columns with rectangular hollow sections are used, as shown by Vandegans [13]. As a matter of fact, similar phenomena occur in the face of the hollow section where the beam is connected.

- For joints subject to bending moment (and shear) and axial compression or tension forces, a specific assembly procedure has to be considered, that corresponds to a particular distribution of the internal forces for stiffness and strength calculation, the component properties remaining unchanged whatever the type of loading. Significant progress in this field has been recently achieved [9].

- Column bases are subjected to combinations of bending moments and axial forces and possess specific components for which a knowledge had to be provided. For instance:

concrete block in compression;

base plates with specific geometry;

anchorages in tension;

contact between soil and foundation;

Such information has recently been published by an international working group [14]. In the report, the validity of the proposed models is shown through comparisons with results of experimental tests and numerical simulations.

- An improvement of the mechanical properties of the joints may be achieved through the use of beam haunches, end-plate stiffeners or high strength steels. These aspects are covered in [9].

- In pitch-roof portal frames, connected beams and columns form an angle higher than $90^{\circ}$. This requires specific amendments to be made to the existing characterisation procedures, see [9].

- When columns with rather slender webs are used, the usual rules for "column web panels in shear" are no more valid because of the apparition of shear buckling and post-critical phenomena. Ad-hoc recommendations are available in [9].

In $[15,16]$, details and rules for the extension of the component method to composite joints are given. The new components to consider are as follows: reinforcement bars in tension; stiffening and strengthening of the column web panel in shear and of the column web in compression by means of encased concrete.

Preliminary works also indicate that the component method also seems suitable for the characterisation of joints subjected to extreme loading conditions such as earthquakes or fire. Besides that, first attempts have been made in the COST $\mathrm{C} 1$ project to apply the component method to joints in precast and timber construction. So it may reasonably be thought nowadays that a unified characterisation procedure for all structural joints is now developing and will be the common basis for the future design codes whatever the material or the combination of materials used. This is likely to lighten the work of the designers, in particular when composite construction is of 
concern and the composite action between the materials is not effective according to the erection stages.

\subsection{Levels of refinement of the component method}

The framework of the component method is sufficiently general to allow the use of various techniques of component characterisation and joint assembly. In particular, the stiffness and strength characteristics of the components may result from experimentations in laboratory, numerical simulations by means of finite element programs or analytical models based on theory. Often experimentation and numerical simulations are used as references when developing and validating analytical models. The latter may be developed with different levels of sophistication:

- expressions as those presented in $\mathrm{PhD}$. theses cover the influence of all the parameters which significantly affect the component behaviour (strain hardening, bolt head and nut dimensions, bolt prestressing,...) from the beginning of the loading to collapse (plasticity, instability, ...);

- rules such as those which have been introduced in the Revised Annex J of Euroc-ode 3 [8] are more simple and therefore more suitable for hand calculations;

- as an ultimate step in the simplification process, simplified calculation procedures and design tables for standardised joints or components have been produced [3,17]; they allow a quick and nevertheless accurate prediction of the main joint properties. Besides that, design software for joints are also available on the market.

Similar levels of sophistication also exist for the joint assembly.

\section{Joint modelling}

\subsection{Generals}

Joint behaviour affects the structural frame response and shall therefore be modelled, just as for beams and columns, for the frame analysis and design. Traditionally, the following types of joint modelling are considered:

For rotational stiffness:

- rigid

- pinned

For resistance:

- full-strength

- partial-strength

- pinned

When the joint rotational stiffness is of concern, the wording rigid means that no relative rotation occurs between the connected members whatever the applied moment may be. The wording pinned postulates the existence of a perfect (i.e. frictionless) hinge between the members. In fact these definitions may be relaxed. Indeed rather flexible but not fully pinned joints and rather stiff but not fully rigid joints may be considered as effectively pinned and perfectly rigid, respectively. The stiffness boundaries allowing one to classify joints as rigid or pinned are discussed in the next section.

For joint resistance, a full-strength joint is stronger than the weaker of the connected members, which is in contrast to a partial-strength joint. In the everyday practice, partial-strength joints are used whenever the joints are designed to transfer the internal forces but not to resist the full capacity of the connected members. A pinned joint is considered to transfer only a limited moment. Related classification criteria are expressed in the next section.

Consideration of rotational stiffness and joint resistance properties leads traditionally to three significant joint models: rigid/full-strength, rigid/partial-strength and pinned.

However, as far as the joint rotational stiffness is considered, joints designed for economy may be neither rigid nor pinned but semi-rigid. There are thus new possibilities for joint modelling: semi-rigid/full-strength and semirigid/partial-strength. 
With a view to simplification, Eurocode 3 accounts for these possibilities by introducing three joint models (Table 1):

Table 1 Types of joint modelling

\begin{tabular}{llll} 
Stiffness & Resistance & & \\
\cline { 2 - 4 } & Full-strength & Partial-strength & Pinned \\
\hline Rigid & Continuous & Semi-continuous & a \\
Semi-rigid & Semi-continuous & Semi-continuous & a \\
Pinned & a & a & Simple \\
\hline
\end{tabular}

${ }^{a}$ Without meaning.

- continuous: covering the rigid/full-strength case only;

- semi-continuous: covering the rigid/partial-strength, the semi-rigid/full-strength and the semi-rigid/partialstrength cases;

- simple: covering the pinned case only.

The following meanings are given to these terms:

- continuous: the joint ensures a full rotational continuity between the connected members;

- semi-continuous: the joint ensures only a partial rotational continuity between the connected members;

- simple: the joint prevents from any rotational continuity between the connected members;

The interpretation to be given to these wordings depends on the type of frame analysis to be performed. In the case of an elastic global frame analysis, only the stiffness properties of the joint are relevant for the joint modelling. In the case of a rigid-plastic analysis, the main joint feature is the resistance. In all the other cases, both the stiffness and resistance properties govern the manner in which the joints should be modelled. These possibilities are illustrated in Table 2.

Table 2 Joint modelling and frame analysis Modelling Type of frame analysis

\begin{tabular}{llll} 
& Elastic analysis & $\begin{array}{l}\text { Rigid-plastic } \\
\text { analysis }\end{array}$ & $\begin{array}{l}\text { Elastic-perfectly plastic and elastoplastic } \\
\text { analysis }\end{array}$ \\
\hline Continuous & Rigid & Full-strength & $\begin{array}{l}\text { Elastic-perfectly plastic and elastoplastic } \\
\text { analysis }\end{array}$ \\
Semi-continuous & Semi-rigid & Partial-strength & $\begin{array}{l}\text { Rigid/partial-strength; semi-rigid/full- } \\
\text { strength; semi-rigid/partial-strength } \\
\text { Pinned }\end{array}$ \\
\hline
\end{tabular}

\subsection{Exact and simplified joint modelling}

The difference between the loading of the connection (bending) and that of the column web (shear) in a beam-tocolumn joint requires, from a theoretical point of view, that account be taken separately of both deformability sources when designing a building frame. However, doing so is only feasible when the frame is analysed by means of a sophisticated computer program which enables a separate modelling of both deformability sources [18]. However for most of the available software, such a sophisticated modelling is not possible and a simplified one (Table 3 ) has to be adopted by concentrating the sources of deformability into a single rotational spring located at the intersection of the axes of the connected members.

For the other joint configurations (beam splices, column bases, ...), this "separation problem" is not of concern and the simplified modelling is used as it closely represents the reality. 
Table 3 Simplified modelling for joints

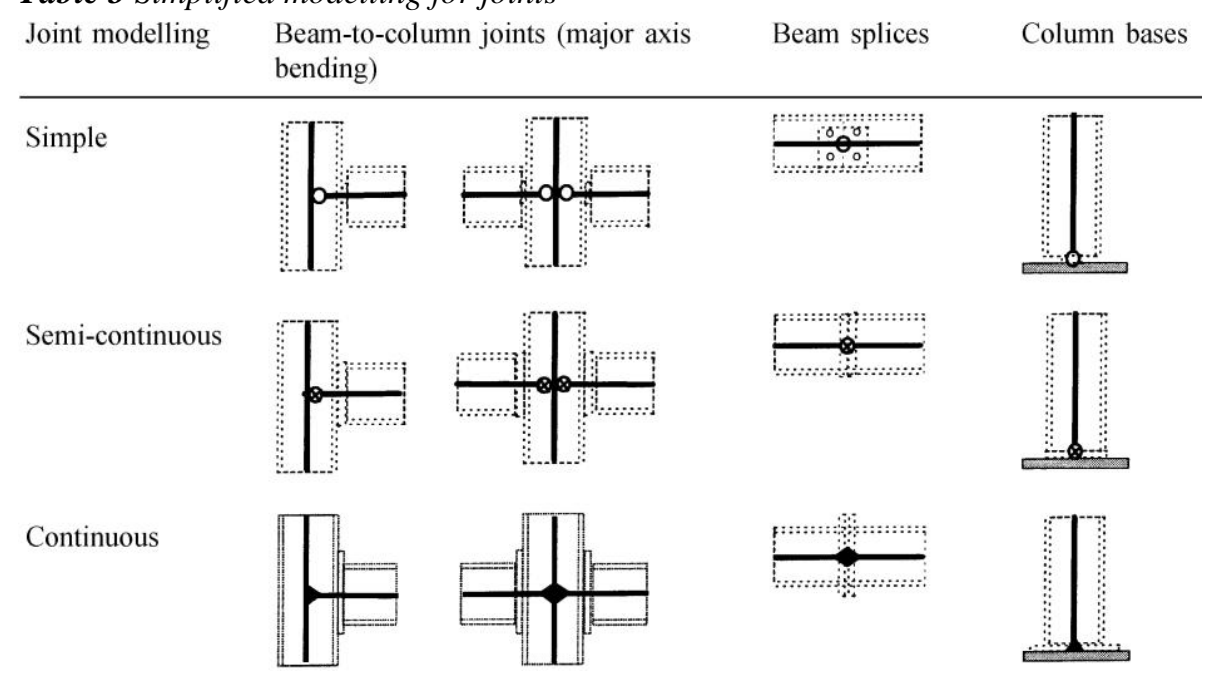

\section{Joint classification}

\subsection{Stiffness classification}

The stiffness classification into rigid, semi-rigid and pinned joints is performed by comparing simply the design joint stiffness to two stiffness boundaries (Fig. 6). For sake of simplicity, the stiffness boundaries are usually derived so as to allow a direct comparison with the initial joint stiffness, whatever the type of joint idealisation that is used afterwards in the analysis.

Different stiffness boundaries have been suggested by some authors. They mainly differ by the criteria used as a basis for classification and the level of the sophistication in their expression. In [19], these proposals are discussed, together with that included in Eurocode 3 Revised Annex J [8].

Fig. 6. Stiffness classification boundaries.

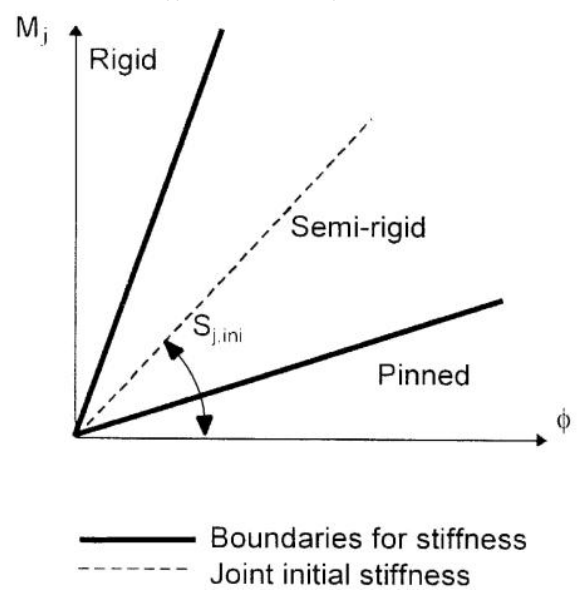

\subsection{Strength classification}

The strength classification simply consists of comparing the joint design moment resistance to "full-strength" and "pinned" boundaries (Fig. 7). The boundaries adopted in Eurocode 3 Revised Annex J [8] seem to be well accepted at the international level and no further discussion on these took place in the last few years. 
Fig. 7. Strength classification boundaries.

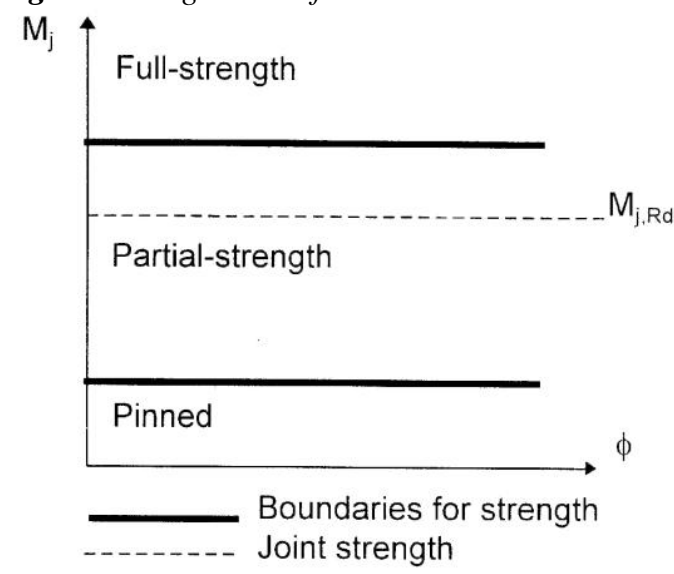

\subsection{Ductility classes}

Experience and proper detailing results in so-called pinned joints which exhibit a sufficient rotation capacity to sustain the rotations imposed on them. For moment resisting joints the concept of ductility classes is introduced to deal with the question of rotation capacity.

Few studies have been devoted to the evaluation of the rotation capacity of joints. This is clearly illustrated in Eurocode 3 Revised Annex $J$ [8] where only a limited amount of information is given. Criteria should therefore be established to distinguish between "ductile", "semi-ductile" and "brittle" joints. Ductile joints are suitable for

plastic frame analysis while brittle ones do not allow any redistribution of internal forces. The use of semiductile joints in a plastically designed frame can only result from a preliminary comparison between the available and required rotation capacities. All this matter is extensively discussed in [19].

Under cyclic loading, the dissipation capacity of the joints is a major parameter to be investigated before allowing the use of partial-strength joints under seismic loading.

\section{Joint idealisation}

The non-linear behaviour of the isolated flexural spring which characterises the actual joint response does not lend itself towards everyday design practice. However the moment-rotation characteristic curve may be idealised without significant loss of accuracy. One of the most simple idealisations possible is the elastic-perfectly plastic relationship (Fig. 8). This modelling has the advantage of being quite similar to that used for the modelling of member cross-sections subject to bending.

The moment $M_{j, R d}$ that corresponds to the yield plateau is termed the design moment resistance in Eurocode 3. It may be considered as the pseudo-plastic moment resistance of the joint. Strain-hardening effects and possible membrane effects are henceforth neglected, which explains the difference in Fig. 8 between the actual $M-\phi$ characteristic and the yield plateau of the idealisation.

The value of the joint constant stiffness $S_{j, \text { ini }} / \eta$ is discussed [9] and practical values are given in Eurocode 3 Revised Annex $J$ [8]. This coefficient results from the high non-linearity of the joint $M$ - $\varphi$ curves in comparison to those of the members. 
Fig. 8. Bi-linearisation of moment-rotation curves.

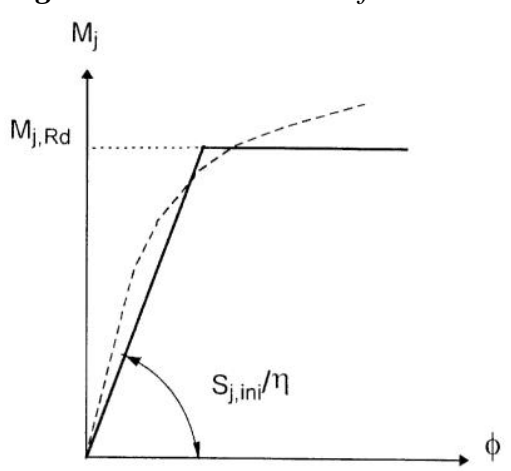

(a) Joint

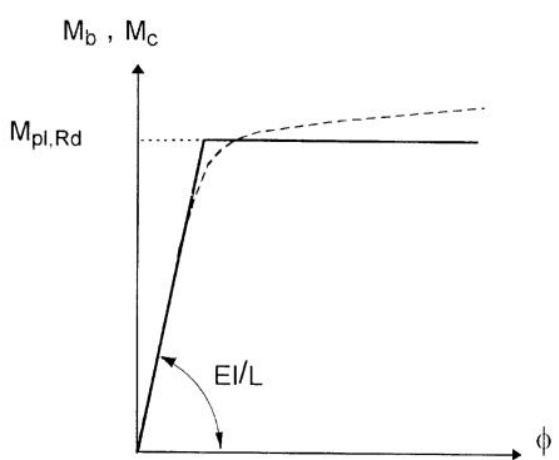

(b) Member

In fact there are different possible ways to idealise a joint $M-\phi$ characteristic. The choice of one of them is dependent upon the type of frame analysis which is contemplated, see Eurocode 3:

- Elastic idealisation for an elastic analysis;

- Rigid-plastic idealisation for a rigid-plastic analysis;

- Non-linear idealisation for an elastic-plastic analysis.

\section{Conclusions}

Much research progress has been achieved in the last years and practical guidelines are now available for most of the steel building frames made of I or I profiles and subjected to static loading. The extension of the design procedures to other types of profiles and to other loading situations is now in progress and results are expected to be obtained through further research projects. One of the main aspects which would focus the attention in the future will be the transfer of these new concepts to practice through appropriate actions (e.g. seminars) and education efforts.

\section{References}

[1] Eurocode 3. Design of Steel Structures. Part 1.1: General Rules and Rules for Buildings, European Prestandard — ENV 1993-1-1, 1992.

[2] SG/TC10a. Momentverbindingen, Staalbouwkundig Genootschap, Branchecentrum Staaltechnologie, Rotterdam, The Netherlands, 1999.

[3] Maquoi R, Chabrolin B. Frame design including joint behaviour, ECSC Report 18563. Luxembourg: Office for Official Publications of the European Communities, 1998

[4] Weynand K. Sicherheits- und Witschaftlichkeits-untersuchungen zur Anwendung nachgiebiger Anschlusse im Stahlbau, Heft 35. Aachen, Germany: Shaker Verlag, 1997.

[5] Kishi N, Chen WF. Steel beam-to-column connections - A review of test data, CE-STR-86-26. West Lafayette, Indiana, USA: School of Engineering, Purdue University, 1986.

[6] Weynand K, Huter M, Kirby PA, Simoes da Silva LAP, Cruz PJS. Sericon - A databank on semirigid joints. Proceedings of the COST C1 International Conference in Liege, September 17-19, 1998, pp. 217-227, Report EUR 18854 EN, Office for Official Publications of the European Communities, Luxembourg, 1999.

[7] Nethercot D, Zandonini R. Methods of prediction of joint behaviour. In: Narayanan R, editor. Structural Connections - Stability and Strength. Elsevier Applied Science Publisher, 1989:23-62.

[8] Revised Annex J of Eurocode 3. Joints in building frames, European Prestandard ENV 1993-1-1:1992/A2. Bruxelles, Belgium: CEN, Bruxelles, 1998.

[9] Jaspart JP. Recent advances in the field of steel joints - Column bases and further configurations for beam-to-column joints and beam splices, Professorship Thesis, Department MSM, University of Liege, Belgium, 1997. 
Published in : Journal of Constructional Steel Research (2000), vol. 55, pp. 69-89

Status : Postprint (Author's version)

[10] COST C1.c. Numerical simulation of semi-rigid connections by the finite element method. In: COST C1 report edited by K. Virdi, European Commission, Bruxelles, Luxembourg, 1999.

[11] Guisse S, Jaspart JP. Influence of structural frame behaviour on joint design. In: Proceedings of the Workshop on Connections in Steel Structures II held in Trento, Italy, on May 29-31, 1995, pp. 321-330, Oxford, U.K.: Elsevier Science, 1996

[12] Steenhuis M, Jaspart JP, Gomes F, Leino F. Application of the component method to steel joints. In: Proceedings of the COST C1 International Conference in Liege, September 17-19, 1998, pp. 125-143, Report EUR 18854 EN. Luxembourg: Office for Official Publications of the European Communities, 1999.

[13] Vandegans D. Use of the threaded studs in joints between I-beams and RHS columns. In: Proceedings of the Istanbul Colloquium on Semi-Rigid Connections held on September 25-27, pp. 53-62. Zurich, Switzerland: IABSE, 1996.

[14] COST C1.a. Column bases in steel building frames. In: COST C1 report edited by Weynand K. Bruxelles, Luxembourg: European Commission, 1999.

[15] COST C1. Composite steel-concrete joints in braced frames for buildings. In: COST C1 report editedby Anderson D. Bruxelles, Luxembourg: European Commission, 1997.

[16] COST C1.b. Composite steel-concrete joints in frames for buildings: design provisions. COST C1report edited by Anderson D Bruxelles, Luxembourg: European Commission, 1999.

[17] BSCA and SCI. Joints in Steel Construction - Moment Connections, Publication 207/95. Ascot, U.K.: The Steel Construction Institute, 1995

[18] Maquoi R, Jaspart JP. Modelling of beam-to-column joints for the design of steel building frames. In: Proceedings of the first World Conference on Constructional Steel Design held in Acapulco, Mexico on December 6-9, pp. 196-205. Barking, Essex, UK: Elsevier Applied Science, 1992

[19] COST C1.d. Recent advances in the field of structural steel joints and their representation in the building frame analysis and design process. In: COST CI report edited by Jaspart JP. Bruxelles, Luxembourg: European Commission, 1999. 